\title{
LANGUAGE CROSSING AND THE PROBLEMATISATION OF ETHNICITY AND SOCIALISATION
}

\author{
Ben Rampton
}

This paper begins in Section 1 by noting two processes that have been generally overlooked in sociolinguistics. Firstly, the prevailing approaches to ethnicity have tended to neglect the processes through which individuals can either adopt someone else's ethnicity, or get together with them and create a new one. Secondly, socialisation in sociolinguistics is most commonly seen as enculturation into an ingroup, not as a process of learning to like and live with social and ethnic difference. To throw some light on these two processes, the paper turns its focus towards a practice it calls 'language crossing' ('code crossing', 'crossing').

Language crossing involves code alternation by people who are not accepted members of the group associated with the second language that they are using (code switching into varieties that are not generally thought to belong to them). This kind of switching involves a distinct sense of movement across social or ethnic boundaries and it raises issues of legitimacy which, in one way or another, participants need to negotiate in the course of their encounter. A fuller account of the intricate dialectic between language, peer group belonging and ethnic otherness that lies at the heart of language crossing emerges as the paper proceeds. After some methodological preliminaries (Section 2) and an outline of some of the ways in which the multiracial peer group I studied can be considered a community (Section 3 ), the empirical description of crossing itself begins with an initial emphasis on the way that crossing was integrated with what was shared in peer group culture (Section 4). The following section (Section 5) turns to the way in which crossing processed ethnic division and race stratification within the peer group. and this is further elaborated in the discussion of socialisation in Section 6. Section 7 contains a conclusion which briefly links crossing's treatment of ethnicity with Bourdieu's discussion of doxa, orthodoxy and heretical discourse.

\section{Some problems in sociolinguistic discussion of ethnicity and socialisation}

The relationship between language, ethnicity and socialisation has been one of the

${ }^{1}$ An earlier draft of this paper was originally presented at the symposium on "Socialisation, Race, Language" at the XIII World Congress of Sociology in Bielefeld, June 1994, and the research it draws on was funded by the Economic and Social Research Council and the Leverhulme Trust. I am very grateful to Celia Roberts and to an anonymous reviewer for comments on an earlier draft. 
founding preoccupations of contemporary sociolinguistics, and so far, it has been understood in two main ways.

\subsection{Ethnicities}

An enormous amount of research has understood ethnicity as the distinctive patterns of language use acquired in the early years at home and in local community networks, and it has looked at the ways that these group specific communicative styles affect interethnic interaction at school and in other public institutions (Labov 1969; Hymes 1972; Cazden et al 1972; Gumperz 1982; Heath 1983; Roberts et al 1992). One problem with this first approach is that it risks an absolutist view of ethnicity as a discrete, homogeneous and fairly static cultural essence, fixed during the early years. Another problem centres on the relationship of ethnicity to other factors: How far is ethnicity the crucial factor in the development of distinctive patterns of communicative competence and in the production of different levels of educational achievement, and how far is it class or gender (cf eg Bernstein 1975; Maltz \& Borker 1982)? Which discursive patterns derive from which identities and in what ways do they interact and exert their influence? In fact, network specific communicative dispositions can play a significant role in the constitution of a wide range of different social identities - on what grounds is priority given to ethnicity (cf Rosen 1985: Heath \& McLaughlin 1993: 6; Gilroy 1987)?

These problems in the first sociolinguistic approach to language, ethnicity and socialisation have been identified, and at least partially overcome, by the second, much more semiotic perspective. Here, rather than being seen as a cultural legacy, ethnicity is regarded much more as a socio-cognitive category that is activated in different ways in different contexts (eg Barth 1969; Moerman 1974; McDermott \& Gospodinoff 1981; Giles \& Johnson 1981; Woolard 1989). In this second approach, ethnicity is a contrastive, positional construct through which participants create, express and interpret a variety of social and political differences, only some of which are connected to early socialisation. Ethnic, class, gender and other identities are seen as situated identities that become interactionally relevant at different times according to varying situational needs and pressures, and one of the most important implications of this approach is that ethnic identities are negotiated rather than fixed, gaining their significance from the character of the particular interactions in which they are activated.

Although this second approach is often seen as a deconstruction of the first (traditional anthropologists may think it makes sense to ask "Who are the Lue", but contemporary analysts know that one really needs to ask "when and why" (Moerman 1974)), these two approaches are by no means necessarily antithetical (see Gumperz \& Cook-Gumperz 1982: 5-6 on how network specific communicative conventions become semiotic resources available for strategic use in intergroup settings), and my own analysis draws elements from both (together with the contested ground that lies between them). There is however one crucial characteristic in this configuration of sociolinguistic views which leaves them unable to do justice to most of the data that I shall discuss in subsequent sections. The anti-essentialism introduced by the contrastive, socio-cognitive approach to ethnicity is generally taken to be the privilege of the analyst. The assumption is that if participants did not feel that it 
reflected primordial bonds and relatively fixed boundaries, ethnicity would not have any meaning for them as an interpretive category (cf eg Fishman 1977: 17-19,23; Gumperz \& Cook-Gumperz 1982: 6-7; LePage \& Tabouret Keller 1985: Ch6; Roosens 1989: 41,160-1). Ordinary people may see their professional and recreational roles as something they perform, but they are supposed to experience ethnicity as a stable and basic part of their background, not as a negotiated accomplishment.

Because participants are assumed to experience ethnicity as an unchangeable inheritance, sociolinguistics produces an image of intergroup communication in which ethnicity is only ever either negative or neutralised. Analysed from the first perspective as an unrecognised but distinctive speech style, ethnicity is liable to lead to communicative breakdown. Analysed from the second perspective as a semiotic category that is either accentuated or attenuated as interaction proceeds, ethnicity entails either race polarisation (eg McDermott \& Gospodinoff 1981; Gumperz \& Cook-Gumperz 1982: 5), or at best, a rather measured bureaucratic hospitality or tolerance (Gumperz, Roberts \& Jupp 1979; Furnborough et al 1982). It is as if individuals are faced with just two options: They can either (a) embrace and cultivate their own ethnicity, or (b) deemphasise it and drop it as a relevant category. What is generally missing is a recognition of the possibility that participants might themselves see ethnicity as something 'produced' rather than simply 'given', 'brought about' as much as 'brought along', and they could encounter a third option: (c) taking on someone else's ethnicity, or creating a new one. Once it is recognised that non-essentialist experiences of ethnicity may be available to ordinary people, multiracial interaction emerges as an arena in which participants could generate a sense of the historic emergence of new allegiances, cross-cutting kinship descent, reworking inherited memberships (though cf Hewitt 1986; Erickson \& Shultz 1981: 30).

This alternative perspective can be linked up with the emergence of what Stuart Hall calls 'new ethnicities' of the periphery:

"We are beginning to see constructions of... a new conception of ethnicity: a new cultural politics which engages rather than suppresses difference and which depends, in part, on the cultural construction of new ethnic identities... What is involved is the splitting of the notion of ethnicity between, on the one hand the dominant notion which connects it to nation and 'race' and on the other hand what I think is the beginning of a positive conception of the ethnicity of the margins, of the periphery... this is not an ethnicity which is doomed to survive, as Englishness was, only by marginalising, dispossessing, displacing and forgetting other ethnicities. This precisely is the ethnicity predicated on difference and diversity" (Hall 1988: 29; see also eg Donald \& Rattansi 1992).

Ethnicity generally involves some combination of a sense of place and of common origin and destiny, shared culture and/or language, a measure of consensus on the evaluation of outgroup 'others', active self-identification with the ingroup, ascription to it by outsiders, and/or some idea of biological kinship and inheritance (cf LePage and Tabouret-Keller 1985: Ch6). There is no reason why all these features should be either synchronised or active simultaneously, and in the emergence of new urban 
ethnicities predicated on difference and diversity, the processes by which ethnic descent is reworked or deemphasised clearly merit close examination, for reasons that are both ethnographic and political.

\subsection{Socialisation}

In fact Hall's idea of an ethnicity "predicated on difference and diversity" also makes it important to reconsider the notion of socialisation. Socialisation is sometimes defined as the process by which a person becomes a competent member of society or their socal group (eg Cook-Gumperz \& Corsaro 1986: 4; Ochs 1988: 5; Schieffelin 199(): 14). But that formulation rather assumes (a) that groups are socio-cultural totalities and (b) that people eventually arrive at an endpoint of expert helonging. What happens if social groups are actually plural and internally fragmented, cross-cut by highly defined (sub-)groupings with cultural resources that many members of the larger group are never likely to be able to either access fully or master properly? Ochs in fact suggests that sociolinguistic studies of socialisation tend to idealise out the plurality of often conflicting practices, values, identities and groupings which children are exposed to from an early age (1986: 10-11), but if we follow Hall's thoughts on a new ethnicity of the margins, these become central.

In trying to understand socialisation into these new mixed ethnicities, two points need to be born in mind. Firstly, this kind of learning to belong in a differentiated community is not a process of taking up a pre-allocated position in a stable and widely accepted social hierarchy. As Hall stresses, ethnic stratification and division are highly contested in contemporary Britain and there is enduring dispute between the absolutist discourses of race and nation on the one hand, and pluralism and egalitarianism on the other. So in the first instance, learning to live with difference is not a matter of enculturation into a well-established ideology of hierarchy, duty and deference.

Secondly, socialisation into culturally heterogeneous peer networks is likely to involve experiences of exclusion that are rather different from the kinds of exclusion most often described in sociolinguistic studies of children's interaction (eg Maynard 1985; Streeck 1986; Corsaro \& Rizzo 1990). There, the distinction between 'friend' and 'enemy' is crucial, and accounts of peer group conflict show how the activation of 'us' vs 'them (him/her)', 'friend vs enemy' generates allegiances and builds a sense of local social structure (Maynard 1985: 207,212; Corsaro \& Rizzo 1990: 46,60). In Zygmunt Bauman's terms,

"The friends/enemies opposition sets apart truth from falsity, good from evil, beauty from ugliness. It also sets apart proper and improper, right and wrong, tasteful and unbecoming. It makes the world readable and thereby instructive. It dispels doubt. It enables one to go on. It assures that one goes where one should." (1990: 144).

In contrast, in situations where cultural pluralism is acknowledged and accepted, moral judgments are harder to make, because people often feel that there are aspects of their peers' knowledge and activity which they are neither equipped nor entitled to judge. Here, exclusion and difference are much more likely to produce 
to uncertainty. In a sense, everyone is a 'stranger' in the polyethnic peer group: everyone is situated

"within a particular... group... But his position in this group is determined by the fact that he has not belonged to it from the begimning, that he imports qualities into it, which do not and cannot stem from the group itself" (Simmel 1950: 402).

In fact according to Bauman, the stranger "calls the bluff of the opposition between friends and enemies as the compleat mappa mundi, as the difference which consumes all differences and hence leaves nothing outside itself... [Strangers] unmask the brittle artificiality of division" (1990: 145,148). The "brittle artificiality of division" takes us back, of course, to Hall's new ethnicities, which embrace differences treated as incompatible in the "the dominant notion... doomed to survive, as Englishness was, only by marginalising, dispossessing, displacing and forgetting other ethnicities".

In sum, in order to understand socialisation into the new ethnicities, we need to examine the ways in which people come to embrace politically fraught differences, the ways in which they manage to develop strong feelings of community which are nevertheless grounded in some permanent uncertainties and an appreciation that they're irremediably incompetent in areas that they really quite care about. We need an account of what happens in socialisation when in opposition to ideologies of hierarchy and division, people learn to live happily with their own exclusion from groups that they actually like and interact with daily.

\section{Some relevant evidence}

I would like to try to throw some light on the 'new ethnicities' and their implications for socialisation by referring to some sociolinguistic research on multiracial friendship groups in Britain. The research focussed on language crossing among adolescents: The ways that youngsters of Asian and Anglo descent used Caribbean based Creole, the ways Anglos and Caribbeans used Panjabi, and the way stylised Indian English ('stylised Asian English' - 'SAE') was used by all three.

Although quantitative sociolinguistics (Labov 1972a; Milroy 1980) served as one initial reference point (see Section 3 and footnote 2 below), the methodologies of ethnographic and interactional sociolinguistics were the most influential, and led to the examination of four closely interrelated dimensions of socio-cultural organisation: (a) language, seen both as a central element in social action, and as a form of knowledge differentially distributed across individuals and groups; (b) the interaction order, particularly as mapped out by Erving Goffman (eg 1983); (c) institutional organisation, encompassing domains, networks, activity types, social roles and normative expectations; and (d) social knowledge specifically as this relates to race and ethnicity. Two years of fieldwork focused on one neighbourhood in the South Midlands of England, with 23 eleven to thirteen year olds of Indian, Pakistani, Afro-Caribbean and Anglo descent in 1984, and approximately 64 fourteen to sixteen year olds in 1987. Methods of data-collection included radio-microphone recording, participant observation, interviewing and retrospective 
participant commentary on extracts of recorded interaction, and the analysis was centred on about 68 incidents of Panjabi crossing, about 160 exchanges involving stylised Indian English, and more than 250 episodes where a Creole influence was clearly detectable.

We can begin the analysis of empirical data with a brief characterisation of the peer group itself and of the language that its members used in routine interaction.

\section{Peer networks and multiracial vernacular English}

All of my adolescent informants during 1984 and 1987 were at the same school (Southleigh Middle in 84, and Newton Upper in 87). Most of them lived in the surrounding neighbourhood, many of them had been at school together since the age of five, and nearly all of them knew each other at least a little bit.

Both among the 11-13 year olds at Southleigh and the 14-16 year olds at Newton, there was a general tendency to associate with peers who were of the same sex and ethnic background (cf also Davey 1983; Thomas 1984). In 1987, for example, I most closely observed about 15 friendship clusters, and in about nine or ten of these, one ethnic group could be said to predominate. A number of informants themselves said that people tended to hang around with others from the same background, and adolescents often referred to ethnicity when identifying different network groupings (as being Indian, black, Pakistani and so forth). So ethnic descent was an important organising principle in the associative networks of local adolescents (for detailed discussion of the 1984 data, cf Rampton 1987: Chs $6,7 \& 12)$.

Even so, in comparison with home and the adult community, school and peer recreation were still important sites for ethnic mixing. In 1984, noone associated exclusively with co-ethnics, and while most friendship cliques were predominantly co-ethnic in 1987, only a small proportion were exclusively so: Though a particular friendship group might be described as 'black' or 'Indian', this often included one or two people with a different ethnic background. Furthermore, a great deal of general sociability occurred in large, polyethnic, mixed sex crowds, and school provided a number of sites for this kind of wider socialising. Lessons were one important setting: 'When you get to know friends in lessons, you can mess about'; 'I know a lot of others - Leela, Marina, and Julie - but I don't hang around with them out of lessons'; 'I reckon more goes on in lessons than there does in six weeks holiday'. Dinner queues and breaktimes were others, and outside school, many adolescents congregated in large groups in parks and youth clubs. ${ }^{2}$

\footnotetext{
2 Admittedly, the social fields that each of these sites made available were constrained in a number of different ways. In lessons, participants were grouped according to an idea of academic ability that wasn't random in the way it is intersected with ethnic descent. Dinner queues only brought together pupils from the same year group. Unofficial social zoning in the upper school recreational areas meant that you couldn't meet a full cross-section of the pupil population if you hung around in only one place. And at the local youth club, you would be much more likely to encounter Pakistani, Anglo and Indian boys than girls, Afro-Caribbeans, Bangladeshis or Italians. Nevertheless, it was within larger gatherings of this kind that male-female relationships were formed,
} 
Analysis of local adolescent networks suggested, then, that a shared ethnic background was of major significance in friendship formation, but that its influence was far from absolute. Subsequent sections will address uses of language which made ethnicity salient, but before then, it is worth stressing that interaction between youngsters from different ethnolinguistic backgrounds also resulted in an ordinary style of English which Hewitt (1986) calls a local multiracial vernacular. Drawing on his own research in mixed white and black areas of London, he writes:

"There has developed in many inner city areas a form of 'community English' or multiracial vernacular which, while containing Creole forms and idioms, is not regarded as charged with any symbolic meanings related to race and ethnicity, and is in no way related to boundary maintaining practices. Rather, it is, if anything, a site within ethnicity is deconstructed, dismantled and reassembled into a new, ethnically mixed, community English. The degree of Creole influence on the specific local vernacular is often higher in the case of young black speakers, but the situation is highly fluid and open to much variation... [This] de-ethnicised, racially mixed local language [operates as]... a constraining, taken-for-granted medium subsisting through all interactions. If there is an 'ethnicity' that is lived in this non-reflexive way it is more likely to reside in the emergent hybrid culture [and language] of black and white urban youth." (Hewitt 1989)

Much the same could be said of the vernacular speech in the neighbourhood I analysed, though here Panjabi was also a significant contributor. As Hewitt notes, it was usually possible to tell where a person's parents came from, but a small quantitative study of two sociolinguistic variables in the relatively informal interview speech of three Caribbean, three Anglo, four Indian and seven Pakistani boys showed a significant degree of confluence and fusion ${ }^{3}$.

and it was here that network clusters came together, defined themselves and sometimes changed their membership. And though to differing degrees, many of these bigger gatherings were multiethnic.

${ }^{3}$ With laterals in post-vocalic, prepausal or preconsonantal environments

- the vocalic L traditionally associated with non-Standard Anglo speech (Wells 1982: 258) was also used by adolescents of Indian, Pakistani and Caribbean descent;

- 'dark' [1] occurred in everyone's speech, inspite of its not typically occurring in Urdu, Panjuabi or Creole;

- traditionally Creole and Panjabi clear [I] (Wells 1982: 5,70; Shackle 1972: 11) was also used postvocalically in the speech of the white informants

- one of whom also used retroflex L, a variant typically associated with Panjabi and Indian English.

Youngsters with a Panjabi background tended to use retroflex $\mathrm{L}$ more than white and black informants. but the extent to which they did so appeared to depend on the extent to which they had multiplex network ties with black and/or white peers - Panjabi bilinguals in the most ethnically exclusive ties used retroflex $\mathrm{L}$ most - and the white boy who used retroflex $\mathrm{L}$ had a greater number of multiplex ties with Panjabi bilinguals than any of the other black or white kids (multiplex ties represented those that involved co-participation in the home and adult community as well as school and peer recreational domains). 
To summarise: Ethnic descent was an important factor in friendship formation in this extended adolescent network. But there was also a lot of ethnic mixing, and although it didn't eliminate subtle ethnolinguistic differences, this resulted in a good deal of similarity in the linguistic patterns that adolescents displayed in routine talk. Both the network and phonological data provide evidence of quite a high degree of commonaiity in peer group culture, and in the next section, this will be elaborated when in some detail, language crossing itself is introduced as a familiar practice in the local adolescent community.

\section{Language crossing in the adolescent community}

In contrast to the tacit linguistic dispositions and practices discussed above, language crossing was generally rather spectacular. Indeed, in so far as it always involved deviation from the linguistic norms of the speaker's habitual speech, crossing was directly counterposed to the local multiracial vernacular.

Although adolescents differed systematically in their abilities, access and allegiance to Panjabi, Creole and stylised Indian English, these three languages all figured prominently in the local social environment, and adolescents used them as auxiliary adjuncts in a range of activities that formed a basic part of the daily round of peer group recreation: Pool, cards, soccer, chasing games; verbal jokes and ritual abuse; listening to music; banter with the opposite sex; and repartee with adults in authority. For example:

(1) Participants: Raymond [13 mixed Anglo/Afro-Caribbean descent; male; wearing radio-mike], Ian [12 Anglo, male], Hanif [12 Bangladeshi descent, male], others

Setting: 1984. Coming out of lessons into the playground at break. Ian and Ray are best friends. Stevie Wonder is a singer whose song 'I just called to say I love you' was very famous. Ray has a bad foot - cf line 17. (Extr III.13)

With voiced TH in word-initial positions, mean use of the plosive variant [d] seemed to be slightly higher among youngsters of Pakistani descent than in any of the other ethnic subgroups. The association between [d] and a Pakistani hackground, however, showed up much more clearly in the cross-ethnic ripple effects picked up by the network measure: Among youngsters with black, white and Indian parents, the use of $[\mathrm{d}]$ was strongly correlated with the extent to which they had multiplex ties with Pakistani peers (the $r$ co-efficient from a Pearson product moment correlation was 0.86 ). With the other variants of word-initial (f), usage was more evenly distributed:

- everyone made a good deal of use of the fricative variant, inspite of its non-occurrence in Panjabi and its apparent rarity in English in India (Wells 1982: 629)

- everyone used zero TH (coalescences and other sandhi forms in post-consonantal environments), inspite of this being described as a London variant by Wells (1982: 329), and inspite of Gumperz's observation that "Indian English speakers ... pronounce almost all consonants with a higher degree of articulation than native speakers" (1982: 121).

For a more detailed account, see Rampton 1987: Ch.13, 1989. 
1 Ray : IA::N::

2 Hanif: (

3 Ian ((from afar)) RAY THE COO:L RAY THE COO:L

4 Hanif: yeh Stevie Wonder YAAA ((laughs loudly))

5 Ray :

6 Ian ((singing)): [it's worser than that

7 Hanif: ha (let's) sing (him) a song

8 Ian : I hate you

9 Hanif: ((loud laughs))

10 Anon ((coming up)): ( ) are you running for the school (.)

11 Ray : huh

12 Anon: are

13 Ray :

14 Anon:=

$\left[\begin{array}{l}\text { you running for the school }= \\ \text { no }\end{array}\right.$

l $1 \mathrm{am}$

Ihe couldnt run for th-he couldnt frun for the school

16 Ray:

17 Ray :=I couldn-I don wan-

18 Hanif:

19 Ian :

20 Hanif: =

21 Ian : $=$ come on

22 Hanif: $=[$ mamıms: $]$

23 Anon: $\quad\left[\begin{array}{l}\text { I came second } \\ \text { cam }\end{array}\right.$

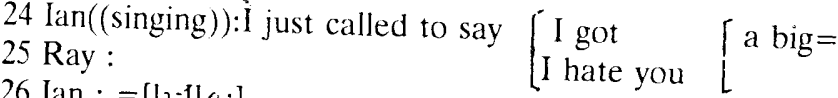

26 Ian : =[1乞-1la:

I can't run anyway

SHUT UP =

((Panjabi for 'willy'))

27 Hanif and others: ((loud laughter $)$ )

28 Ray ((continuing Ian's song)): so's Ian Hinks (1.5)

29 ((Ray Laughs)) no you haven't you got a tiny one (.)

30 you've only got (a big arse)

In this extract, Ian mixed Panjabi with Stevie Wonder in some jocular abuse directed at his good friend Ray. When he started out in lines 6 and 8 , he seemed to be identifying himself with the first person expressed in the song, but when he repeated it in lines 24 and 26, it looks as though he was putting the words in Ray's mouth rather than claiming the 'I' for himself - certainly, Ray's retaliation in line 28 suggests that it was him that had been attributed the item in Panjabi, not Ian. Whatever, Ian came off best in their brief exchange of ritual abuse: Ian's [lvila:] upstaged Ray's effort to preempt him in line 25; it was Ian who won an enthusiastic response from third parties in line 27; and in lines 29 and 30, Ray evidently judged his own immediate retort (line 28) as itself rather weak.

Ian only knew a few words in Panjabi, and even then, his grasp was rather insecure ("I understand most of what they're saying when they're saying 'phuddoo' and this to me... and 'mari bunji' and all this.... oh no..'murri bunji', I don't know what that means, I just made that up I think"). Rather than representing the kind of smooth code alternation often found in the speech of fluent bilinguals, the switch in Extract 1 was conspicuously sited in the punchline, and it instantiated a form of 
agonistic Panjabi code-switching that was widely commented on by my informants (cf Rampton 1991b, 1995: Chs 2.2 \& 7). Indeed, in contrast to the highly critical reception of spectacular white incursions into Creole generally given by black (and other) adolescents in Hewitt's data (1986: 150-1,162; see also Milroy 1980: 60-1), responses to Panjabi switches like these were usually quite enthusiastic (Rampton 1995: 42-3), and indeed as already indicated, in the laughter in line 27, Ian's effort met with acclaim.

A fairly comprehensive account of the factors contributing to Ian's success will only emerge in the next section when the potential problematicity of language crossing is properly addressed. But in the first instance, it is worth underlining the initial value of following Ochs (1988: 6) and seeing the local adolescent peer group as a loosely identifiable socio-cultural collectivity, with a shared set of orientations, practices and standards of competent conduct. Among other things in Extract 1, language crossing was clearly embedded within good friendship, shared knowledge of popular music, and up to a point at least, familiarity and common acceptance of jocular abuse (which in this peer group, adolescents called 'blowing'; cf Labov 1972b; Goodwin \& Goodwin 1987). In the course of their recreational activity more widely, individuals negotiated a variety of interactional and institutional identities (eg games player, joker, fellow pupil, opponent in blowing, chaser and chased in tag, attractive member of the opposite sex), and they also built up personal ties of familiarity, esteem, affection or dislike. So when it occurred and made ethno-linguistic inheritance a relevant issue, language crossing was always set within the (generally supportive) context of a range of non-racial identities that had already been activated.

So a common peer group culture played a significant role facilitating language crossing. In fact, crossing's relationship with peer group culture was often more active than this perhaps implies: It was sometimes actually used in interaction to inculcate or restore conduct consistent with 'normal' adolescent propriety. At the start of the new school year, for example, a senior student could turn to a new one and use stylised Asian English to tell them that they should have grown out of chasing games:

(2) Participants and setting: At the start of the school year, Mohan [15 years, Indian descent, male, wearing radio-microphone], Jagdish [15, In, M] and Sukhbir [15, In, M] are in the bicycle sheds looking at bicycles at the start of the new academic year. Some new pupils run past them. (III.3)

1 Sukh: STOP RUNNING AROUND YOU GAYS (.)

2 Sukh: $\quad[(($ laughs $))$

3 Moh: [EH (.) THIS IS NOT MIDDLE (SCHOOL) no more (1.0)

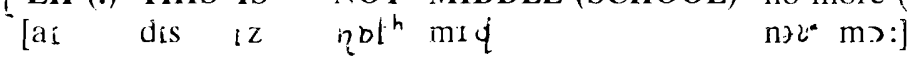

4 this is a re, spective (2.0)

[dis iz $\rightarrow$ lospektiv]

$5 \quad:$ (school)

6 Moh: school (.) yes (.) took the words out my mouth (4.5) 
In this extract, Mohan was claiming that the norms of conduct appropriate to secondary pupils during breaktime had been broken, and Goffman's account of remedial interchanges (1971: 95-187) helps to explain the way that stylised Asian English (SAE) figured in the episode. Goffman argues that two kinds of issue arise when infractions occur. One of these is 'substantive', relating to practical matters such as the offender making amends and the offended showing that they are not going to accept the way they have been treated. The other kind of issue is ritual, which in contrast, is concerned with the way in which participants display their more general respect and regard for social norms and personal preserves (Goffman 1971: $95-98,100,116)$ - here the concern is with "indicating a relationship, not compensating a loss" (1971: 118).

In line 1 , the initial noticing of the infraction was announced by a normal vernacular English 'prime' - an attempt to get the (putative) offender to provide a remedy which they might do by desisting, apologising and/or giving an explanation (Goffman 1971: 154ff, 109-114). Propositionally, the utterance in line 3 only reminded the (disappearing) addressee that old rules of conduct no longer applied, but the switch to stylised Asian English made a symbolic proclamation about the transgression's relation to a wider social order. In switching away from his normal voice to SAE, Mohan aligned the offence with a more general social type, so that the offending act was now cast as a symptom. SAE was stereotypically associated with limited linguistic and cultural competence (see below) and the switch implicitly explained the transgression by imputing diminished control and responsibility to the offender ${ }^{4}$.In doing so, it achieved the same effect as a sanction: "The significance of... rewards and penalties is not meant to lie in their intrinsic worth but in what they proclaim about the [actor's] moral status... and [their] compliance with or deviation from rules in general" (Goffman 1971: 95,98). (See also Rampton 1995: Ch 6.2).

Creole could also be used in the affirmation of peer group norms. In the following extract, immediately after visibly coming off worse in a verbal tussle with

\footnotetext{
${ }^{4}$ In the interpretation here, SAE is being used as a 'say-for', as a voice deemed representative of the addressee/target rather than the speaker (cf. Goffman 1974: 535 and Section 6). An alternative account might reject this, and propose instead that SAE represented a voice of Panjabi adult authority which, in reprimanding a younger pupil, Mohan was claiming for himself. There are, however, at least four difficulties with such an alternative. In the first place, it presupposes that parents of bilingual Panjabi adolescents reprimanded their children in English rather than Panjabi, despite the fact that informants generally said (a) that Panjabi, despite the fact that informants generally said (a) that Panjabi was used as much at home as English (Rampton 1987: 176-82), and (b) that Panjabi was associated with politeness and respect. Secondly, if SAE was used in criticism as a language of parental authority, why would it be addressed to youngsters, of Bangladeshi descent, about whom Panjabi adolescents diddn't feel at all paternal (see Section 5)? Thirdly, how could SAE as a language of authority be reconciled with the image of babu deference and incompetence, which it also often made quite explicit in Panjabi accented utterances like "I no understand English", "excuse me, Miss", and "after you"? And lastly, in interracial arenas, bilinguals occasionally commented rudely on the accented Indian English of adults, and so it couldn't be argued that SAE was universally respected as a language of authority. All in all, the explanation offered in the main body of the text seems more coherent. It is also perhaps worth adding as an afterword that this account does not insist that the symbolic connotations evoked by SAE were invariant - in fact, it can be fitted quite effectively with the way in which SAE's symbolic resonances seemed to vary according to activity type (Rampton 1995: Chs6 \& 9.5).
} 
the teacher, an adolescent turns to his friend and produces some Creole to repair his loss of face:

(3) Participants: Asif [15 years old, Pakistani descent, male, wearing radio-microphone], Alan [15, Anglo-descent, M], Ms Jameson [over 25, An F], and in the background, Mr Chambers [25+ An M]

Setting: 1987. Asif and Alan are in detention. Ms Jameson is saying why she arrived late for the detention, and now she wants to go and fetch her lunch. (II.17)

80 Ms J: I had to to and see the headmaster

81 Asif: why

$82 \mathrm{Ms} \mathrm{J}: \quad$ ( ) (.) none of your business

83 Alan: a-about us ( )

$84 \mathrm{Ms}$ J: no I'll be back

85 Asif: Lhey how can you see the $=$

86 =headmaster when he was in dinner (.)

$87 \mathrm{Ms} \mathrm{J}: \quad$ that's precisely why I didn't see him

((1.))

88 Asif: what (.)

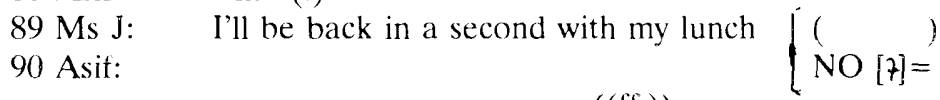

$91 \quad=$ dat's sad man (.) (I'll b ) $=$ ((f.))

92

$=\mathrm{I} \quad\left[\begin{array}{l}\text { had to miss my play right I've gotta go } \\ \left(\begin{array}{c}\text { with mine } \\ \text { ( })\end{array}\right)\end{array}\right.$

3 Alan:

(2.5) ((Ms J must now have left the room))

95 Asif

((Creole influenced $))$ : ll:unch (.) you don't need no $=$

((f.))

[1l: $\wedge$ nt $\}]$

$96=$ lunch $\left[\begin{array}{l}\text { not'n grow anyway ((laughs)) } \\ {\left[\text { nat }_{n} \text { ges.) v] }\right.}\end{array}\right.$

97 Alan:

98 Asif: $\quad$ have you eat your lunch Alan

Lines 80-88 of this extract involve a verbal tussle in which Asif and Alan use questions to undermine the positions that Ms Jameson stakes out in what she says. Asif's question in line 81 treats the account she gives of her late arrival as inadequate; she rejects his inquiry as illegimate in line 82 but this is then undermined by Alan in lines 83 and 84; and in lines 85-87, Ms Jameson is delayed in the departure she announced in line 84 by a question that upgrades the query over her initial excuse into an explicit challenge. All this time, she has been locked into the interaction by the adjacency structures set up by the boys' questions, but at line 89 , she breaks out of this pattern, ignores Asif's line 88 repair initiation, again 
announces her departure and leaves without saying anything more. With the cooperative exchange structure now disrupted, Asif launches into some 'afterburn'/"muttering':
"Afterburn... is ... a remonstrance conveyed collusively by virtue of the fact that its targets are in the process of leaving the field... when one individual finds that others are conducting themselves offensively in their current dealings with him... he can wait until they have closed out the interchange with him and turned from the encounter, and then he can express what he 'really' feels about them... he may turn to a member of his encounter... and flood into directed expression" (Goffman 1971: 152,153)
"In muttering we convey that although we are now going along with the line established by the speaker (and authority), our spirit has not been won over, and compliance is not to be counted on" (Goffman 1981: 93)

In this afterburn, Asif uses some Black English/Creole. Admittedly, it is sometimes difficult to distinguish Creole from the local multiracial vernacular (cf Hewitt 1986: 128-9 and below), and Asif's stopped TH in "dat's sad man" is ambiguous. But in lines 95 and 96, he uses a distinctly Creole unrounded front open vowel in "not" (cf Wells 1982: 576; Sebba 1993: 153-4), and the stretched and heavily voiced L in his first "lunch" maybe connects with a black speech feature noted by Hewitt in South London (1986: 134). Creole (and/or London Black English) synchronises with a turn that refutes any notion of meek pupil submission on Asif's part, and seems to reaffirm his reputation for lively adolescent assertiveness.

Finally, language crossing was itself sometimes referred to as a sign of local peer group membership:

(4) Setting: 1987 interview

Participants (\& referents): Ben - over 30 years old, male, Anglo descent; Faizal - 14, M, Pakistani descent; Manwar - 14, M, Pakistani descent; Billy and Peter - 14, M, Anglo))

Manwar: we've nicknamed Billy a few... I dunno, (for) about a year, in our school half, half... half-jabber $((=$ Asian $))$

Faizal: he's half-jabber now - knows most of the words - and so's Peter, he knows quite a lot of ((Panjabi)) words too

Manwar: yeh, these two are one of us

(5) Setting: 1987 interview

Participants (\& referents): Ben - over 30 years old, male, Anglo descent;

Faizal - 14, M, Pakistani descent; Kuldip - 14, M, Indian descent; Peter - 14, $\mathrm{M}$, Anglo

Ben: $\quad$ so who would you say knows most ((Panjabi))

Faizal: $\quad$ Peter

Kuldip: $\quad$ yeh, he knows, he's been in our sort of community

Faizal: he's been our friend long time 
Setting: 1987 playback session

Participants: Ben and Peter (14, M, Anglo)

Peter: 'gora' - white man ((in Panjabi))... I always call the people who didn't go to Southleigh ((local middle school)) 'goras', yet I'm white myself

Ben: the kids who didn't go to Southleigh you say

Peter: yeh, cos we reckon they're, you know, a bit upper class

(7) "all of us you know Asian guys, we can use ((Creole)) well you see, cos we've all been talk... you know speaking it since Southleigh second years ((the age of ten))" [Informant: 15 years old, Pakistani descent, male]

In this section, then, we have considered three aspects of crossing's integration within local peer group culture. Firstly, and rather obviously, crossing was facilitated by some quite extensively shared orientations, practices and standards. Secondly, it was sometimes used spontaneously to draw identities and conduct back into line with peer group norms and ideals. And thirdly, it was explicitly cited as emblem of peer group belonging. The emphasis so far has been on crossing's relationship with the socially cohesive aspects of local multiracial peer group life. Commonality has been stressed more than diversity and difference. It is important now to turn to the way in which language crossing registered the potential conflicts and divisions that also ran through the local adolescent community.

\section{Language crossing and the evocation of race difference}

Both Creole and stylised Asian English carried a complex set of symbolic connotations, and although a comprehensive account would also need to reckon with their more intimate family associations (cf Rampton 1995: Ch2.4), part of their social meaning was influenced by wider politics of race in Britain. Asian English had quite wide media currency in stereotypic potraits of British Asians (Dummett 1973: 279; Goffe 1985), and it frequently conjured 'babu' images of linguistic incompetence and bumbling deference inherited from the days of the British Raj (Yule and Burnell [1886] 1985: 44). The mass public image of Creole was more varied, and its association with music and popular culture gave it considerable prestige among youth (cf Hewitt 1986: Ch3; Rampton 1995: Chs2.1 \& 9). At the same time, it was also stereotypically associated with tough assertiveness and opposition to authority (Hewitt 1986; Rampton 1995). The result was that in Hewitt's data, black adolescents tended to see white Creole use "(a) as derisive parody, and hence as an assertion of white superiority, and (b) as a further white appropriation of one of the sources of power" (1986: 162). To a considerable degree, in combination stylised Asian English and Creole constituted variations on the victim/ problem, clown/threat couplets recurring in the discourses of British racism (Gilroy 1987; Walvin 1987).

These highly problematic symbolic associations immediately complicate the picture of language crossing as a local community practice outlined in the previous section. How could multiracial peer group community be consolidated by the 
evocation of dangerous images like these? The faultines of race difference transected the peer group internally and so anyone wanting to use an ethnic outgroup language had to bear in mind the possibility that there might be non-intimate ethnolinguistic inheritors on hand who could take legitimate offence at the expropriation of a valued resource (particularly with Creole), and/or at the reductive imagery which crossing frequently entailed.

There are two answers to this, and they relate back to the two notions of exclusion outlined in Section 1.2 - one hingeing on the 'friend/enemy' dichotomy, and the other involving an interplay between 'strangeness' and 'belonging'. I shall discuss the former only rather briefly, although it is important to recognise the operation of what was in effect an often racist dichotomy for at least two reasons. Firstly, recognition of it helps us to avoid romanticising interracial peer group processes, and secondly, in what follows, it can also serve as a useful reminder that we cannot claim to be dealing with some 'essence of peer group': The focus is on one or two from a wide range of linguistic and cultural practices, some of which promoted and projected particular notions of community and otherness, and some of which didn't.

With regard, then, to the first, 'friends/enemies' notion of exclusion, it became clear during interviews that language crossing was felt to be neither legitimate nor likely among posh whites and youngsters of Bangladeshi descent (even though the radio-microphone data reveals that at least among Bangladeshis, crossing was quite common). This pointed to a sense of class and race stratification that was very influential among my informants. In this folk schema, non-local white boys and Bangladeshis were typified as contrasting points of negative reference that helped to define the 'normal', and they formed a number of polar contrasts between which 'ordinary' adolescents could situate themselves and their friends. Posh Anglos were said to reside in wealthier villages and districts outside the neighbourhood, while Bangladeshis were generally seen as living in much poorer accommodation in the central parts of town. Posh white kids were associated with private school, with high curriculum sets at Newton Upper and with proper English, while Bangladeshis were linked to the local ESL reception centre, remedial classes at Newton and inadequate second language varieties of English. Neither of these class and race stereotypes was unproblematic or uncontested, and when reflecting on it, adolescents generally felt quite guilty about their treatment of Bangladeshis in particular. Even so, the term 'Bengali' was repeatedly used in 'humourously' critical remarks about the conduct of associates, Bangladeshis were endlessly associated with unsociability, unfashionable dressing and other undesirable characteristics, they were almost entirely excluded from my informants' friendship networks, and lastly, they were also subjected to quite aggressive uses of stylised Asian English (eg Rampton 1995: 143-4).

So the account of exclusion in terms of a 'friends/enemies' opposition certainly reflects the way ratified members of the local peer group regarded Bangladeshis and most posh whites, and most of the time with these two groups,

5 It perhaps ought to be added that in their perception of posh whites, local peer group members sometimes made an exception with girls (cf. Rampton 1995: Ch2 on this intricate interaction between class, race and gender). 
peer group members really didn't care whether they used stereotypes that caused offence. This is not however adequate as an account of the way they responded to exciusion and difference, since it only refers to people with whom relations were generally unfriendly, neglecting the fact that most friendship clusters were themselves ethnically mixed. To understand Hall's new ethnicities, we need to dwell at greater length on the interplay between strangeness and belonging, and on the way in which language crossing handled ethnic differences internal to the network of recognised peer group members.

The language crossing of adolescents showed sensitivity to the different ethnic backgrounds of their friends in two general strategies. First and most obviously, by not crossing in certain contexts (avoidance). Black and white adolescents seldom used stylised Indian English to target Panjabi triends, and most whites and Panjabis either avoided Creole or used it in very circumscribed ways when they were in the company of black peers (Hewitt 1986: Ch5; Rampton 1995: Chs 6 \& 8). Secondly, crossing generally only occurred in moments, activities and relationships in which the constraints of ordinary social order were relaxed and normal social relations couldn't be taken for granted.

In extract 1 for example, in combination with friendship and a number of other factors (cf Rampton 1995: Chs 7.3.7.4, 7.8), the formulaic use of song meant that for a brief interlude, the exchange of abuse was ritual and jocular rather than personal and serious (cf Labov 1972: Goodwin \& Goodwin 1987). In the other two examples of spontaneous discourse, crossing was closely tied up with breaches of some kind or other: Mohan's stylised Aslan English in Extract 2 rebuked a new pupil's impropriety, and in Extract 3 , it was an explicit sense of injustice and injury that led inio Asit's semi-resilient Creole in lines 95 and 96. As both Goffman and Gartinkel make abundantly clear, breaches, improprieties and transgressions disrupt our everyday sense of social reality.

In fact in one form or another, routine assumptions about ordinary life seemed to he temporarily relaxed, suspended or jeopardised whenever adolescents code-crossed. These interruptions to the routine flow of normal social order took a wide range of different forms, and varied very considerably in their scale and duration. As well as cueing or being cued by delicts, transgressions and ritual abuse, adolescents code-crossed at the boundaries of interactional enclosure, when the roles and identities for ensuing interaction were still relatively indeterminate (Goftman 1971: Ch 7; Laver 1975): in self-talk and response cries, which constituted time away from the full demands of respectful interpersonal conduct (Goffman 1981: 81,85,99); in games. where there was an agreed relaxation of routine interaction's rules and constraints (Handelman 1977; Turner 1982: 56; Sutton-Smith 1982); in the context of performance art (cf Gilroy 1987: 210-216); and in cross-sex interaction, which in a setting where everyday recreation was single sex and where many parents discouraged unmonitored contact between adolescent girls and boys, itself seemed special, unusually vested with both risk and promise (Foley 1990: 33,70,95: Shuman 1993: 146). So in one way or another, crossing was occasioned by (or occasioned) moments and events in which the hold of routine assumptions about social reality was temporarily loosened. In all of these moments and events, "the world of daily life known in common with others and with others taken for granted" (Gartinkel 1984: 35) was problematised or partially suspended (see Rampton 1995 for comprehensive exemplification). 
We can summarise this aspect of language crossing by saying that it was profoundly connected with liminality and the 'liminoid' (Turner 1982) ${ }^{6}$, and from this, we can draw two inferences. Firstly, its intimate association with liminality meant that crossing never actually claimed that the speaker was 'really' black or Asian - it didn't finally imply that the crosser could move unproblematically in and out of their friends' heritage language in any new kind of open bicultural code-switching. Secondly, crossing's location in the liminoid margins of interactional and institutional space implied that in the social structures which were dominant and which adolescents finally treated as normal, the boundaries round ethnicity were relatively fixed.

So language crossing cannot be seen as a runaway deconstruction of ethnicity, emptying it of all meaning: Inherited ethnicity was something that adolescents treated as a basic feature of routine social reality, and in this regard, the interactional data corroborated the data on patterns of friendship, as well as a large number of other aspects of local cultural and material life. But this doesn't mean that adolescents submitted reverentially to ethnic absolutism. If what Hall calls the dominant, dispossessing, 'race' and nation notion of ethnicity had been hegemonic, language crossing would have been unacceptable, a ceaseless source of local conflict. It wasn't. Inherited ethnicity certainly wasn't rejected or abandonned, but neither was its influence left unquestionned, invisibly and incontrovertibly pervading common sense. Crossing was one interactional practice in the repertoire of peer group activity that foregrounded ethnicity itself, and in doing so, it at least partially destabilised it.

When adolescents code-crossed with friends, there was in fact a tension in the way that they treated the boundaries round an ethnic category. They both respected and transgressed them, and in this light, crossing can be interpreted as a process of delicate political negotiation. In excess, both an acceptance and a

${ }^{6}$ 'Liminality' is a concept developed by Victor Turner in particular, drawing on anthropological studies of initiation rites in tribal and agrarian societies. These rites have three phases: Separation, in which initiands leave their childhood life behind; transition; and then incorporation, in which they are returned to new, relatively stable and well-defined positions in society, now a stage further on in life's cycle (Turner 1982: 24). Turner concentrates on the transitional middle phase, which he calls 'liminal":

"during the intervening phase of transition... the ritual subjects pass through a period and area of ambiguity, a sort of social limbo which has few.. of the attributes of either the preceding or subsequent social statuses or cultural states... In liminality, [everyday] social relations may be discontinued, former rights and obligations are suspended, the social order may seem to have been turned upside down" (Turner 1982: 24, 27).

It is not possible to argue directly from this account of traditional ritual to the kinds of urban social relationship addressed in my own research. But Turner extends the notion of liminality into a form that fits more easily with practices common in industrial society, and he calls these 'liminoid' ('oid' meaning 'like', 'resembling' but not identical). The distinction between liminal and liminoid can be hard to draw, but while, for example, liminal practices tend to contribute to the smooth functioning of social systems, liminoid practices are often creative, containing social critiques and exposing wrongs in mainstream structures and organisation (1982: 45). Similarly, liminality tends to involve symbols with common intellectual and emotional meaning for all members of the group, while "liminoid phenomena tend to be more idiosyncratic, quirky, to be generated by specific named individuals and in particular groups" (1982: 54). For fuller discussion in the context of language crossing, see Rampton 1995: Ch.7.9. 
disregard for these boundaries could slip into injustice, which can be defined as either (a) treating people the same when in relevant respects they are different, and/or as (b) treating them as different when in relevant respects, they are similar (Halstead 1988: 154). For adolescents in a multilingual peer group, unrestricted use of an ethnic outgroup language could constitute the first kind of injustice; on the other hand, if an individual resisted every temptation to experiment in an outgroup code, they might also find that they had actually succumbed to the second. Crossing generally wove a path between these two forms of racism. Through it, adolescents actively explored the waterline where ethnic and interracial forms and practices overlapped and intermingled with each other and here they challenged (b) - ethnic fixity and division. But at the same time, they normally only brought out their improvisations and new acquisitions in places where it could be safely understood that they weren"t making any claims to real, equal or enduring membership of an ethnic outgroup. So in this way, they also avoided (a) - the insensitivity to difference instantiated elsewhere in race relations in 'colour blindness', ethnocentrism and so forth.

Looking back, then, over the account given in this section and the one before it, it is possible to see how language crossing links directly into the the tension between similarity and difference pinpointed in Hall's new 'ethnicity of the margins'.

On the one hand, crossing emerges as a practice closely tied to the shared norms, values and activities of a particular cultural collectivity. It required a specific kind of interactional competence to situate the use of outgroup codes in liminal moments and events. Crossing showed sensitivity to a complex set of situational contingencies - the stage and state of talk, the activity type, the institutional setting, the relationship between interlocutors and so forth - and as a skillful, group-specific practice, effective and accepted crossing generally only came with substantial experience of local multiracial peer group life. In this respect, as well as in its explicit function as emblem of group identity, language crossing was intimately associated with belonging in new form of multiracial community.

But at the same time, crossing also invoked difficult and dangerous knowledge of ethnic difference and race stratification, using them to enhance or protect the performance of local adolescent recreation. Evidently, adolescents experienced ethnic division as more than just 'brittle artificiality', but it wasn't treated as absolute, and in code-crossing, they played with the redefinition of group boundaries in discursive acts that involved a complex combination of violation and regard. In this respect, crossing looks like a significant contribution to the emergence of a sense of youth community 'predicated on difference and diversity', and the account given here is one way in which sociolinguistic analysis can illuminate the interethnic processes highlighted in Section 1.1. But what of socialisation?

\section{Perspectives on socialisation}

So tar, my account has emphasised the group dimensions of language crossing - on the one hand, its integration with local culture, its use in the support of adolescent norms, its citation as evidence of peer group membership, and on the other, its engagement with intergroup politics in society at large. The empirical discussion has also taken socialisation rather for granted, treating adolescent community practice 
only as an endstage of competent conduct. But what did crossing mean for particular speakers, and what did it say about the social development of individuals in a multiracial setting?

A full account of the processes of trial, error and correction involved in white adolescents learning to use Creole is provided by Hewitt (1986: Ch5). My own analysis of these is less detailed, and I have rather less to say on how individuals actually learnt to cross in ways that were accepted in the local youth community (socialisation into the peer group as a first hand experience). Nevertheless, as a generic practice, language crossing repeatedly foregrounded incompetence, instruction, temporality, personal change and individual social positioning, and through it, at the level of behavioural ideology (Volosinov 1973: 91-2), adolescents continually engaged with central issues in socialisation. To complete the account of how language crossing figured in the attempts that adolescents made to live with difference, it is essential to provide a brief outline of the ways in which crossing into Panjabi, Creole and stylised Asian English displayed a range of subtly differentiated concerns with learning and social development.

With Panjabi, being an effective and accepted crosser generally involved an ability to exploit and enjoy incompetence itself. Adolescents competent and ratified in the ways of multiracial peer group culture often participated in interethnic activities which announced, accepted and indeed sometimes celebrated a lack of linguistic proficiency. For example, in playground interaction among boys in early adolescence, it was quite common for Panjabi bilinguals to invite monolingual friends of Anglo and Afro-Caribbean descent to either say things in Panjabi, or to respond to Panjabi questions ${ }^{7}$. These invitations to use another language normally contained elements which lay just beyond the learner's grasp, and the fact that an important element of what was being said to the second language learner was incomprehensible to them was crucial, generating a great deal of the entertainment (see Rampton 1991a: 230-4, 1995: Ch 7). Learners had to operate just beyond the limits of their linguistic competence, and playfully speaking, their reputations depended on their performance. Here is an example:

(8) Participants: Mohan (male, 13 years, Indian descent, wearing a radio-microphone), Sukhbir (M 13 In), Jagdish (M 13 In), David (M 12 Afro-Caribbean), Pritam (M In), others

Setting: Breaktime outside. Mohan, Jagdish and David are best friends

1 Jagdish ((turning to David, speaking in Panjabi)):

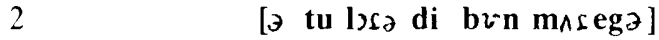

((Approximate translation: do you want to bum Laura?))

3 Sukhbir: 「ha ha ha ha ha

${ }^{7}$ Among monolinguals of Anglo and of Caribbean descent, there was a small stock of Panjabi words and phrases in general circulation, and this comprised a selective if rather predictable cocktail of nouns referring to parts of the body, bodily functions, animals, ethnic groups and kin; adjectives describing personal physical attributes; verbs of physical violence and ingestion; and a few other items (cf. Rampton 1991a: 395-6, 1995: Ch.7.1). It was generally some part or parts of this collective lexicon, which few individuals commanded in its entirety, that featured in the utterances that Panjabi bilinguals tried to get their friends to engage with. 
4 Others: $\perp$ ((laughter for about three seconds))

5 David: no I don't think so

6 Jagdish: DAVID (.) no I said that- that means that you're-

7

8 David: no=

9 Sukhbir: =yeh it does, it does [(it does)

10 David: ((smile voice)) [that- that means [h] are you

11 going to make her pregnant=

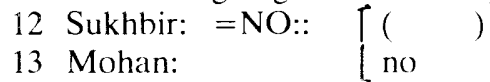

((a few moments later))

21 Jagdish: SAY IT TO HIM (.) say it to him say it to him

22 Others: $\left[\begin{array}{l}\text { say it to him [mesi mãdi } \\ ((\text { Panjabi. Trans: my mum's fanny })) \\ ((\text { laughter }))\end{array}\right.$

24 Anon: go on

25 David: I [don't want to say that

26 Jagdish: LNO SAY IT TO HIM GO ON say it to him

27 Anon: ha $[$ ha ha ha ha

28 Anon:

29 David:

30

31 Jagdish:

32

$\left\{\begin{array}{l}\text { ho on } \\ \text { (it says-your go- ) }\end{array}\right.$

it means that $\left[\begin{array}{l}\text { MY mum's got a - } \\ \text { eh? }\end{array}\right.$

no say ((... the 'elicitations' continue $))$

Here, a minimal and unconfident knowledge of Panjabi was drawn into traditional playground practice, in variations on the verbal routines which the Opies describe as 'incrimination traps' (Opie \& Opie 1959: Ch4) ${ }^{8}$. Placed in situations of this kind, a number of strategies were available to an L2 Panjabi speaker aware of the insufficiency of their linguistic knowledge, and in this extract, David's could be characterised as a knowing refusal. Another commonly used tactic was to ask a friend:

(9) "my friend, you know, he swears in Panjabi to English girls, and they go and ask an Indian boy they know, and he tells them and tells them other words and they come and say it to us"

Consultations of this kind were very commonly construed in pupil-teacher terms ("if they're our friends, we teach them it"), although as illustrated in the episode above,

\footnotetext{
8 Typical examples in English would be "Adam and Eve and Pinchmetight went down to the sea to bathe, Adam and Eve were drowned and who do you think was saved?", and
A: "Count on. I one a rat."
B: "I two a rat."
C: "I three a rat."

and so on up to "eight".
} 
you'd be foolish to trust too much in the instruction that these provided:

(10) "like Ishfaq tells... you know Alan Timms, if Alan Timms says 'teach me some dirty words', Ishfaq makes him say swear words to himself ((laughs)), so he's saying it to hims... he goes up to Asif and he says it and Asif starts laughing"

Particularly among 11 to 13 year old white and black boys, a high level of incompetence in Panjabi generated a range of entertaining recreational activities, and when asked, they said they wouldn't be interested in attending any formal Panjabi classes. They didn't want to improve their proficiency in Panjabi, and were evidently quite happy to remain permanently as pre-elementary language learners. The rudimentary Panjabi L2 learner was a significant and enjoyable local identity.

Stylised Asian English also made linguistic competence a relevant issue, though in a much more politically charged way than Panjabi. In a great deal of its use, the symbolic meaning of interracial Panjabi was relatively unaffected by the wider context of race stratification. In contrast, as I have already indicated in section 5, SAE often evoked 'babu' stereotypes of deference and incompetence. In addition, Asian English was also associated both with adults who had come to England from India and Pakistani (towards whom informants often expressed solidary sentiments), and with recently arrived Bangladeshi peers (towards whom they were generally hostile - cf Rampton 1988 and 1995: 2.4 on the ambiguous and troublesome connotations of Asian English).

In all of its connotations, Asian English conjured a past that Panjabi adolescents now felt that they were leaving behind. It evoked an historical time frame of migration and contact and this seemed to impact on the self-voice relationships expressed in spontaneous discourse. Adolescents used SAE in a variety of ways: Probing the intergroup perceptions of adults in authority by feigning mock deference or incomprehension (Rampton 1995: Ch 3; forthcoming); abusing Bangladeshi peers; reprimanding junior pupils; jokily attributing impropriety or incompetence to friends (Rampton 1995: Ch 6). But when they did so, there was generally a clear distinction between self and voice, 'principal' and 'figure' (Goffman 1974): In Bakhtin's terms, the 'double-voicing' was varidirectional (1984: 193). ${ }^{9}$

\footnotetext{
${ }^{9}$ Double-voicing is a term that Bakhtin uses to describe some of the ways that this heteroglossia acts upon the utterance. With double-voicing, speakers use someone else's discourse (or language) for their own purposes,

"inserting a new semantic intention into a discourse which already has... an intention of its own. Such a discourse... must be seen as belonging to someone else. In one discourse, two semantic intentions appear, two voices." (Bakhtin 1984: 189)

Bakhtin describes several kinds of double-voicing, and one of these is described as 'uni-directional'. With uni-directional double-voicing, the speaker uses someone else's discourse "in the direction of its own particular intentions" (1984: 193). Speakers themselves go along with the momentum of the second voice, though it generally retains an element of otherness which makes the appropriation conditional and introduces some reservation into the speaker's use of it. But at the same time, the boundary between the speaker and the voice they are adopting can diminish, to the extent that there is a "fusion of voices". When that happens, discourse ceases 10 be double-voiced, and instead becomes 'direct, unmediated discourse' (1984: 199). The opposite of uni-directional double-voicing is varidirectional double-voicing, in which the speaker "again speaks in someone else's discourse, but
} 
Addressed to another adolescent either in mock or in serious criticism (cf Extract 2), SAE was used as a 'say-for' (Goffman 1974: 535), attributing the persona it evoked to the target, not claiming it for the speaker, and indeed it seemed to achieve its effect as a negative sanction for deviant conduct by threatening the recipient with regression, symbolically isolating them on a path of historical development now abandonned by adolescents who had arrived at an endpoint that they now took for granted.

Admittedly, the claim here for an intimate connection between a practical sense of historical temporality on the one hand, and on the other, the manner in which Asian English was interactionally exploited, requires rather more supporting evidence than there is space to provide here (though cf Rampton 1995: Chs 3, 4 and 6 ). Even so, it is worth adding that the data on Creole crossing suggested a link of the same kind, even though in its particular character, it seemed to be the exact opposite of SAE. In contrast to Asian English, Creole stood for an excitement and excellence in vernacular youth culture which many youngsters aspired to, and it was even described as 'future language'. In line with this, Creole crossing generally ressembled Bakhtin's uni-directional double-voicing, and self and voice were often closely entwined. Certainly, there was usually some reservation in the way it was used by whites and Asians, and this was indicated both by the way they avoided it in the presence of black peers and by its location in liminal moments and events. Even so, crossers tended to use Creole to lend emphasis to evaluations that synchronised with the identities they maintained in their ordinary speech, its use lent power to the speaker, and when directed towards deviance, it often expressed approval. Consistent with this, as Hewitt (1986: 148,151) emphasises and as is illustrated in the discussion of Extract 3, Creole crossing headed towards fusion with, and was often hard to disentangle from, the local multiracial vernacular (cf Bakhtin 1984: 199 on 'uni-directional double-voicing' shifting over into 'direct unmediated discourse').

In sum, as a form of practical consciousness, language crossing displayed a recurrent preoccupation with issues central to the discussion of socialisation. In cross-ethnic Panjabi, adolescents made play with knowledge and ignorance, instruction and deceit. To describe stylised Asian English and Creole, we can borrow Goffman's terms (1967: 56,77) and say that SAE projected an image of too much deference and not enough demeanour while the Creole persona had an excess of demeanour over deference, and the suggestion is that together they represented poles of tear and desire on a path of historical development, one standing for regression and the other for advance.

But the difference between the way that socialisation was represented in crossing and the way that it is usually discussed in the academic literature lies in the fact that in crossing, hardly anyone finally arrived. Instead, crossing generally constituted multiracial adolescence as a world of uncertainty and movement, towards and away from other-ethnic inheritances. Certainly, some youngsters aspired to become uncontested members of the black or Panjabi youth community, and some

\footnotetext{
... introduces into that discourse a semantic intention directly opposed to the original one". In varidirectional double-voicing, the two voices are much more clearly demarcated, and they are not only distant hut also opposed (Bakhtin 1984: 193).
} 
got much closer than others, particularly when the contexts were romance or performance art (cf Hewitt 1986; Rampton 1995: Chs 9.2,10.6,10.8 for a discussion of particular cases). But finally, the boundaries round ethnicity were relatively fixed in the social structures that which were dominant and which adolescents treated as normal, and although it varied a lot in its insistence and intensity, a sense of anomaly was always close at hand whenever crossers moved outside the identities displayed in habitual vernacular speech. In fact for many adolescents, this was central to crossing's attraction. Although it needed to be accessed through the proper channels, and although there were clear constraints on the display of its creations, crossing represented an interest in travelling around the borderlands themselves, in being both near and different, close and apart. Crossing revelled in not-yet- or never-to-be-realised potentiality itself.

\section{Conclusion}

Among sociolinguists, there has been a good deal of debate about whether ethnicity is best seen as a cultural inheritance that participants bring along with them to interaction, or whether it is more properly regarded as a construct that they bring about in interactional discourse itself (cf eg Meeuwis and Sarangi 1994). Conceptually, this paper doesn't actually resolve the argument in favour of one term or the other (cf Bourdieu 1977), but it shifts the floor of the debate and in doing so, throws up empirical phenomena with a social significance that sociolinguistics perhaps hasn't yet fully appreciated. ${ }^{10}$

The paper suggests that at the level of behavioural ideology, there was an unsettled debate about group-membership-as-acquired-disposition and group-membership-as-situated-performance being conducted in the code crossing practices of a multiracial adolescent peergroup. Ethnolinguistic inheritance was forgotten neither in the interactional practice and nor in the social organisation of local adolescents, and in their treatment of youngsters with Bangladeshi descent, it was embraced with virulence. But at the same time, through language crossing, youngsters temporarily denaturalised both ethnicity and socialisation in a series of acts which thematised change in ethnic identity and cultivated a spectacular, dynamic, heteroglossic marginality. Defined as a discursive practice in which speakers moved across ethnic (or social) boundaries and used languages that weren't generally thought to belong to them, language crossing itself crystallised in adolescent culture something very similar to the tension between ethnicity-as-communicative-inheritance and ethnicity-as-discursive-construct.

If awareness of this tension between the brought-along and brought-about is regarded as an exclusively academic affair, if the interactional negotiation of ethnic category membership is only seen as something which participants do without

${ }^{10}$ There are in fact a number of accounts with a good deal of descriptive similarity to my own account of language crossing: for example, Hill \& Coombs 1982; Wooloard 1988; and most obviously Hewitt 1986. But in general, the distinctiveness of language crossing is lost, and it is either swallowed up under the rubric of code-switching, or misconstrued as second language acquisition (cf. Rampton 1995: Ch11 for further discussion). 
actually knowing, then for participants, experiencing ethnicity in interaction can only involve either the defence or affirmation of 'roots' (hostility or unease in intergroup situations, rapport with the ingroup). There is no scope for seeing how participants could change their ethnic identities: New interactional experiences could only either be assimilated to ethnicity as given, or lead to its internal renovation (or alternatively, be treated as simply irrelevant). The issue of which individuals had the potential to be aligned with which ethnic categories would itself remain unproblematised.

If, on the other hand, inherited ethnicity is foregrounded in a set of activities which actually confront it with the possibility of negotiated ethnicities, then plainly, the hold of ethnicity as inheritance is no longer absolute. In Bourdieu's terms, it has lost its authority as doxa, it is no longer "accepted undiscussed, unnamed, admitted without scrutiny", and can instead only hope to become "the necessarily imperfect substitute, orthodoxy" (1977: 169-70).

This is exactly what seemed to happen in language crossing. Ethnic descent was credited with a lot of authority in routine social reality, but it was regularly transgressed in liminal moments and events when adolescents invoked, explored and momentarily inhabited ethnicities other than their own. Metaphorically speaking, crossing stopped ethnolinguistic inheritance from being an unnoticed, all-encompassing superordinate frame, and drew it down into the 'picture' itself (cf Bourdieu 1977: 168). In this commentary on ethnicity, crossing constituted a form of "political action [which]... aims to make or unmake groups... by producing, reproducing or destroying the [mental, verbal, visual or theatrical] representations that make groups visible for themselves and for others" (Bourdieu [1981] 1990: 127). More specifically, juxtaposed to ethnic inheritance as an orthodoxy which adolescents themselves often embraced, crossing can be seen as a form of 'heretical discourse' which helped "to sever the adherence to the world of common sense by publicy proclaiming a break with ordinary order" (Bourdieu [1981] 1990: 129; cf Sections $5 \& 6$ above).

According to Bourdieu, beyond simply problematising the world of common sense, heretical discourse

"must also produce a new common sense and integrate within it the previously tacit or repressed practices and experiences of an entire group, investing them with the legitimacy conferred by public expression and collective recognition" ([1981] 1990: 129)

It is not possible here to discuss the extent to which language crossing either instituted a new common sense or developed from behavioural to established ideology (cf Rampton 1995: Ch12). Plainly, crossing itself was not unconstrained as form of public expression, and collective recognition of it was not invariably approving. Nevertheless, it is clear that language crossing has the potential to play an important part in the emergence of 'new ethnicities' 'predicated on difference and diversity', and that as such, it is a practice that merits a lot more sociolinguistic attention. 


\section{CONVENTIONS USED IN TRANSCRIPTION}

$\underline{\text { Segmental phonetics }}$

[ ] IPA phonetic transcription (revised to 1979)

\section{Conversational features}

overlapping turns

$=\quad$ two utterances closely connected without a noticeable overlap, or different parts of a single speaker's turn

(.) pause of less than one second

(1.5) approximate length of pause in seconds

1. lenis (quiet) enunciation

f. fortis (loud) enunciation

CAPITALS fortis (loud enunciation)

(( )) 'stage directions'

( ) speech inaudible

(text) speech hard to discern, analyst guess

Bold instance of crossing of central interest in discussion

\section{References}

Bakhtin M. (1984) Problems in Dostoevsky's Poetics. Minneapolis: University of Minnesota Press.

Barth F. (1969) Introduction. In F. Barth (ed), Ethnic Groups and Boundaries. London: Allen \& Unwin, pp. 9-39.

Bauman Z. (1990) Modernity and ambivalence. Theory, Culture and Society 7: 143-169.

Bauman Z. (1992) Intimations of Postmodernity. London: Routledge.

Bernstein B. (1971) Class Codes and Control. Volume 1. London: Routledge Kegan Paul.

Bourdicu P. (1977) Outline of a Theory of Practice. Cambridge: Cambridge University Press.

Bourdieu P. [1981] (1990) Language and Symbolic Power. Oxford: Polity Press.

Cazden C., V. John, and D. Hymes (eds) (1972) Functions of Language in the Classroom. New York: Teachers College Press. 
Cook-Gumperz J., and W. Corsaro (1986) Introduction. In J. Cook-Gumperz, W. Corsaro, and J. Streeck (eds), Children's Worlds and Children's Language, pp. 1-11.

Cook-Gumperz J., W. Corsaro, and J. Streeck (eds) (1986) Children's Worlds and Children's Language. Berlin: Mouton de Gruyter.

Corsaro W., and T. Rizzo (1990) Disputes in the peer culture of American and Italian nursery-school children. In A. Grimshaw (ed), Conflict Talk. Cambridge: Cambridge University Press, pp. 21-66

Davey A. (1983) Learning to Be Prejudiced. London: Edward Arnold.

Donald J., and A. Rattansi (eds) (1992) 'Race' Culture and Difference. London: Sage.

Dummett A. (1973) A Portrait of English Racism. Harmondsworth: Penguin. (2nd Edition 1984. London: CARAF.)

Erickson F., and J. Shultz (1981) The Counsellor as Gatekeeper. New York: Academic Press.

Fishman J. (1977) Language and ethnicity. In H. Giles (ed), Language, Ethnicity and Intergroup Relations. New York: Academic Press, pp. 15-57.

Foley D. (1990) Learning Capitalist Culture. Philadelphia: University of Pennsylvania Press.

Furnborough P., T. Jupp, R. Munns, and C. Roberts (1982) Language disadvantage and discrimination: Breaking the cyle of majority group perception. Joumal of Multilingual and Multicultural Development 3: 247-66.

Garfinkel H. (1984) Studies in Ethnomethodology. Oxford: Polity Press.

Giles H., and P. Johnson (1981) The role of language in ethnic group relations. In J. Turner, and H. Giles (eds), Intergroup Behaviour. Oxford: Blackwell, pp. 199-243.

Gilroy P. (1987) There Ain't No Black in the Union Jack. London: Hutchinson.

Goffe A. (1985) Black and Brown in Brum. Guardian 19.9.1985

Goffman E. (1967) Interaction Ritual. Harmondsworth: Penguin.

Goffman E. (1971) Relations in Public. London: Allen Lane.

Goffman E. (1974) Frame Analysis. Harmondsworth: Penguin.

Goffman E. (1981) Forms of Talk. Oxford: Blackwell.

Goffman E. (1983) The interaction order. American Sociological Review 48: 1-17.

Goodwin M., and C. Goodwin (1987) Children's arguing. In S. Philips, S. Steele, and C. Tanz (eds), Language, Gender and Sex in Comparative Perspective. Cambridge: Cambridge University Press, pp. $200-48$.

Gumperz J. (1982) Discourse Strategies. Cambridge: Cambridge University Press.

Gumperz J. (ed) 1982 Language and Social Identity. Cambridge: Cambridge University Press. 
Gumperz J., and J. Cook-Gumperz (1982) Introduction: Language and the communication of social identity. In J. Gumperz (ed), pp. 1-21.

Gumperz J., T. Jupp, and C. Roberts (1979) Crosstalk: A Study of Cross-cultural Communication. Southall Middlesex: National Centre for Industrial Language Training.

Hall S. (1988) New ethnicities. ICA Documents 7: 27-31.

Halstead M. (1988) Education, Justice and Cultural Diversity: An Examination of the Honeyford Affair. Lewes: Falmer Press.

Handelman D. (1977) Play and ritual: Complementary frames of meta-communication. In A. Chapman, and H.Foot (eds), It's a Funny Thing, Humour. Oxford: Pergamon, pp. 185-192.

Heath S.B. (1983) Ways with Words. Cambridge: Cambridge University Press.

Heath S., and M. McLauglin (1993) Identity and Inner City Youth: Beyond Ethnicity and Gender. New York: Teachers College Press.

Hewitı R. (1986) White Talk Black Talk. Cambridge: Cambridge University Press.

Hewitt R. (1989) A sociolinguistic view of urban adolescent relations. Paper presented to conference on 'Everyday life, cultural production and race', Institute of Cultural Sociology, University of Copenhagen 27028, April.

Hill J., D. Coombs (1982) The vernacular remodelling of national and international languages. Applied Linguistics 3: 224-34.

Hymes D. (1972) On communicative competence. In J. Pride, and J. Holmes (eds), Sociolinguistics. Harmondsworth: Penguin, pp. 269-293.

Labov W. (1969) The logic of non-standard English. In Georgetown Monographs on Language and Linguistics 22. Washington DC: Georgetown University Press.

Labov W. (1972a) Sociolinguistics Patterns. Oxford: Blackwell.

Labov W. (1972b) Rules for ritual insults. In Language in the Inner City. Oxford: Blackwell.

Laver J. (1975) Communicative functions of phatic communion. In A. Kendon, R. Harris, and M. Key (eds), Organisation of Behaviour in Face-to-Face Interaction. The Hague: Mouton, pp. 289-304.

LePage R., and A. Tabouret Keller (1985) Acts of Identity. Cambridge: Cambridge University Press.

Maltz D., and R. Borker (1982) A cultural approach to male-female miscommunication. In J. Gumperz (ed), pp. 195-216.

Maynard J. (1985) On the functions of social conflict among children. American Sociological Review 50: 207-223.

McDermott R., and K. Gospodinoff (1981) Social contexts for ethnic borders and school failure. In H. Trueba, G. Guthrie, and G. Au (eds), Culture and the Bilingual Classroom. Rowley: Newbury House, pp. 212-230.

Meeuwis M., and S. Sarangi (1994) Perspectives on intercultural communication. Pragmatics 4.3: 309-13. 
Milroy L. (1980) Language and Social Networks. Oxford: Blackwell.

Moerman M. (1974) Accomplishing ethnicity. In R. Turner (ed), Ethnomethodology. Harmondsworth: Penguin, pp. 54-68.

Ochs E. (1986) Introduction. In B. Schieffelin, and E. Ochs (eds), Language Socialisation across Cultures. Cambridge: Cambridge University Press, pp. 1-13.

Ochs E. (1988) Culture and Language Development. Cambridge: Cambriơge University Press.

Opie I., and P. Opie (1959) The Lore and Language of Schoolchildren. Oxford: Oxford University Press.

Rampton B. (1987) Uses of English in a Multilingual British Peer Group. Unpublished Ph.D. thesis: University of London Institute of Education.

Rampton B. (1988) A non-educational view of ESL in Britain. Journal of Multilingual and Multicultural Development 9.6: 503-529.

Rampton B. (1989) Group affiliation and quantitative sociolinguistics. York Papers in Linguistics 13: 279-294.

Rampton B. (1991a) Interracial Panjabi in a British adolescent peer group. Language in Society 20: 391.422 .

Rampton B. (1991b) Second language learners in a stratified multilingual setting. Applied Linguistics 12.3: $229-248$.

Rampton B. (1995) Crossing: Language and Ethnicity among Adolescents. London: Longman.

Roberts C., E. Davies, and T. Jupp (1992) Language and Discrimination. London: Longman.

Roosens E. (1989) Creating Ethnicity: The Process of Ethnogenesis. London: Sage.

Rosen H. (1985) The voices of communities and language in classrooms. Harvard Educational Review 55.4: $448-56$.

Schieffelin B. (1990) The Give and Take of Evenday Life. Cambridge: Cambridge University Press.

Sebba M. (1993) London Jamaican. London: Longman.

Shackle C. (1972) Panjabi. Norwich: English Universities Press.

Shuman (1993) 'Get outa my face': Entitlement and authoritative discourse. In J. Hill, and J. Irvine (eds), Responsibility and Evidence in Oral Discourse. Cambridge: Cambridge University Press, pp. $135-60$.

Simmel G. (1950) The stranger. In K. Wolff (ed), The Sociology of Georg Simmel. New York: Free Press, pp. $402-408$.

Streeck J. (1986) Towards reciprocity: Politics, rank and gender in the interaction of a group of schoolchildren. In J. Cook-Gumperz, W. Corsaro, and J. Streeck (eds), pp. 295-326.

Sutton-Smith B. (1982) A performance theory of peer relations. In K. Borman (ed), The Social Life of Children in a Changing Society. Norwood NJ: Ablex, pp. 65-77. 
Thomas K. (1984) Intercultural relations in the classroom. In M. Craft (ed), Education and Cultural Pluralism. Lewes: Falmer Press, pp. 57-77.

Turner V. (1982) From Ritual to Theatre: The Human Seriousness of Play. New York: PAJ.

Volosinov V. (1973) Marxism and the Philosophy of Language. Massachusetts: Seminar Press.

Walvin J. (1987) Black caricature: The roots of racialism. In C. Husband (ed), 'Race' in Britain: Continuity and Change. 2nd Edition. London: Hutchinson, pp. 59-72.

Wells J. (1982) Accents of English Volumes 1-3. Cambridge: Cambridge University Press.

Woolard K. (1988) Codeswitching and comedy in Catalonia. In M. Heller (ed), Codeswitching: Anthropological and Sociolinguistic Perspectives. The Hague: Mouton de Gruyter, pp. 53-76.

Woolard K. (1989) Double Talk. Stanford: Stanford University Press.

Yule H., and A. Burnell (1886) Hobson Jobson: Glossary of Anglo Indian Colloquial Words and Phrases. Reprinted 1985. London: Routledge Kegan Paul. 